\section{Impacted Foreign Body at the Pharyngoesophageal Junction: An Innovative Management}

The majority of foreign bodies in the upper gastrointestinal tract can be retrieved endoscopically [1] with the help of forceps, basket or snare [2]. We report an innovative method of removal of an impacted foreign body at the pharyngoesophageal junction.

A ten-year-old boy ingested a plum without chewing, two days prior to presentation, followed by absolute dysphagia. Examination revealed a dehydrated child with tachycardia and hypotension. Administration of intravenous fluids was begun and the patient underwent endoscopy under sedation. This revealed a large globular fruit with a taut peel impacted at the pharyngoesophageal junction. Gentle force using the tip of the endoscope could not force the fruit down. An attempt at suction retrieval, using the cylinder of variceal ligator was unsuccessful. Repeated attempts at basketing the fruit failed because it was not possible to pass the closed basket across the impacted fruit. A cutting current was applied to the peel of the fruit to make a $0.5 \mathrm{~cm}$ hole with needle knife sphincterotome. The needle was further introduced into the pulp of the

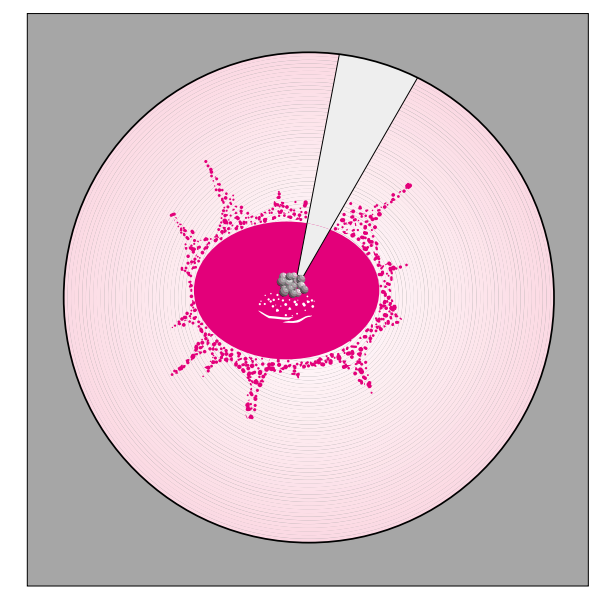

Figure 1 Schematic representation of needle knife cauterization of the impacted plum fruit at pharyngoesophageal junction fruit and a blended current was passed in all the four quadrants to pulverize the pulp and soften the fruit (Figure 1). The tip of the endoscope was then applied to the hole on the peel of the fruit and pulp suctioned out, leading to further softening and decrease in size of the fruit. Gentle force was applied by the tip of the endoscope to disimpact the now soft and smaller sized fruit into the fundus of the stomach where it was grasped by basket and retrieved.

The application of a cautery current applied to bipolar snare to cut into, grasp, and retrieve an impacted food bolus in the esophagus has been reported [3]. In the present case cautery current was used to cut open the peel of the fruit and pulverize the pulp, to make it softer and smaller facilitating its subsequent removal.

\section{S. Nijhawan, L. Shimpi, N. K. Jain, R. R. Rai \\ Department of Gastroenterology, SMS Medical College \& Hospital, Jaipur, India}

\section{References}

${ }^{1}$ Webb WA. Management of foreign bodies of the upper gastrointestinal tract: Update. Gastrointest Endosc 1995; 41: 39-51

${ }^{2} \mathrm{Kim}$ JK. Management of foreign bodies in the gastrointestinal tract. An analysis of 104 cases in children. Endoscopy 1999; 31: $302-304$

${ }^{3}$ Mackenzie TL, Antonino S. Bipolar cautery snare capture and removal of esophageal food bolus obstruction. Gastrointest Endosc 1992; 38: 186 - 187

\section{Corresponding Author}

\section{S. Nijhawan, M.D.}

Department of Gastroenterology SMS Medical College and Hospital 87, Panchsheel Enclave Gokul Bhai Bhat Marg Durgapura, Jaipur - 302017 Rajasthan

India

Fax: $\quad+91-141-520163$ 